\title{
CXCR4 inhibitor attenuates ovalbumin-induced airway inflammation and hyperresponsiveness by inhibiting Th17 and Tc17 cell immune response
}

\author{
HUILONG CHEN $^{1}$, XIANGQIN XU $^{1}$, JIEMING TENG ${ }^{1}$, SHENG CHENG $^{1}$, HANSVIN BUNJHOO $^{1}$, YONG CAO $^{1}$, \\ JIN LIU ${ }^{1}$, JUNGANG XIE ${ }^{1}$, CONGYI WANG ${ }^{2}$, YONGJIAN XU ${ }^{1}$ and WEINING XIONG ${ }^{1}$ \\ ${ }^{1}$ Department of Respiratory and Critical Care Medicine and ${ }^{2}$ Center for Biomedical Research, Tongji Hospital, \\ Key Laboratory of Pulmonary Diseases of the Health Ministry, Tongji Medical College, \\ Huazhong University of Science and Technology, Wuhan, Hubei 430030, P.R. China
}

Received December 6, 2014; Accepted January 28, 2016

DOI: $10.3892 /$ etm.2016.3141

\begin{abstract}
Accumulating evidence suggests that chemokine (C-X-C motif) ligand 12 (CXCL12) and its receptor chemokine (C-X-C motif) receptor 4 (CXCR4) may contribute to the pathogenesis of allergic asthma. However, the underlying molecular mechanisms remain to be fully understood. T-helper 17 cells (Th17) and T-cytotoxic 17 cells (Tc17) have been implicated in the development of several allergic disorders, including asthma. The present study aimed to explore the association between CXCL12 signaling and Th17/Tc17 cells in the development of asthma. Ovalbumin (OVA)-sensitized BALB/c mice were treated with AMD3100, a specific CXCR4 antagonist, prior to OVA challenge. Following the final allergen (OVA) challenge, airway responsiveness to methacholine, influx of inflammatory cells to the airway, and cytokine levels in the bronchoalveolar lavage fluids (BALF) and lung homogenate were assessed. Interleukin (IL)-17-expressing $\mathrm{CD}^{+}{ }^{+} \mathrm{CD} 8-$ lymphocytes (Th17 cells) and IL- $17^{+} \mathrm{CD}^{+} \mathrm{CD}^{+}$lymphocytes ( $\mathrm{Tc} 17$ cells) isolated from lung tissue samples were detected by flow cytometry. The results of the present study demonstrated that administration of AMD3100 significantly decreased airway responsiveness to methacholine, attenuated the influx of inflammatory cells to the airway and reduced the levels of IL-4, IL-5 and IL-13 in the BALF. Furthermore, AMD3100 significantly reduced the increased number of lung Th17 and Tc17 cells as well as the levels of IL-17 in the lung homogenate induced by OVA
\end{abstract}

Correspondence to: Professor Weining Xiong, Department of Respiratory and Critical Care Medicine, Tongji Hospital, Key Laboratory of Pulmonary Diseases of the Health Ministry, Tongji Medical College, Huazhong University of Science and Technology, 1095 Jiefang Avenue, Wuhan, Hubei 430030, P.R. China E-mail: xiongdoctor@hotmail.com

Key words: C-X-C chemokine receptor type 4, asthma, T-helper 17 cells, T-cytotoxic 17 cells challenge. In conclusion, the CXCR4 inhibitor suppresses the asthmatic response, which is associated with attenuation of the Th17 and Tc17 cell immune response.

\section{Introduction}

Asthma is a chronic disease characterized by airway inflammation, airway hyperresponsiveness (AHR) and reversible airway obstruction. Although the precise mechanism underlying this response remains to be fully elucidated, it is now generally believed that asthma arises as a result of dysregulated immune responses in which T-helper (Th) 2 cells have a central role in the pathogenesis and pathology (1).

Chemokine (C-X-C motif) ligand 12 (CXCL12), also known as stromal cell-derived factor-1, is a member of the chemokine family, which consists of low molecular-weight proteins $(8-15 \mathrm{kD})$ produced by various types of cells involved in allergic inflammation (2). CXCL12 binds to chemokine (C-X-C motif) receptor 4 (CXCR4) and attracts a variety of cells, including resting $\mathrm{T}$ lymphocytes, monocytes, CD $34^{+}$stem cells and mature eosinophils (3). CXCL12 and its receptor CXCR4 have been demonstrated to be involved in Th2-type allergic airway responses, and inhibition of CXCL12 or CXCR4 leads to reduced airway inflammation and AHR (4-6). Furthermore, another study demonstrated that the levels of CXCL12 were significantly higher in bronchoalveolar lavage fluids (BALF) of asthmatic patients compared with healthy individuals, and the concentration of CXCL12 was correlated with inflammatory cell numbers in the BALF (7). These results suggested that CXCL12 may contribute to inflammatory cell recruitment in asthma.

Interleukin (IL)-17 is a pro-inflammatory cytokine that is expressed in the airways of patients with asthma (8), and its expression is correlated with the severity of asthma (9). The concentration of IL-17 was significantly increased in the BALF, sputum and blood of patients with asthma $(8,10,11)$. Furthermore, IL-17 or IL-17R-deficient mice exhibit reduced allergic airway inflammation $(10,12)$. These results demonstrate the importance of IL-17 in the induction of allergic airway inflammation. 
IL-17-producing CD4 ${ }^{+} \mathrm{T}$ cells (Th17 cells) are a distinct subset of T helper cells similar to Th1 and Th2 cells (13-16). It has been demonstrated that Th17 cells enhance Th2 cell-mediated eosinophilic airway inflammation in mice (13). A corresponding subset of IL-17-secreting $\mathrm{CD}^{+} \mathrm{T}$ cells [T-cytotoxic 17 (Tc17) cells] similar to the Th17 cells also exists (17). Our previous study demonstrated an increased proportion of Tc17 cells in the peripheral blood of patients with asthma compared with healthy controls, as well as in the spleen cells and lung tissue samples of asthmatic mice (18). These data support both Th17 and Tc17 cells may have a role in the regulation of allergic airway inflammation.

Although both experimental and clinical data support that CXCL12/CXCR4 signaling and Th17/Tc17 cells are involved in the pathogenesis of asthma, their association during the course of asthmatic responses however remains unknown. It is proposed that blockade of CXCR4 may suppress the asthmatic response associated with the attenuation of Th17 and Tc17 cell infiltration in the lung. Therefore, the anti-inflammatory effect of a CXCR4 antagonist, AMD3100, on Th2-type cytokines, inflammation cell infiltration and AHR using an ovalbumin (OVA)-induced murine asthma model, was investigated. In addition, the effects of AMD3100 on the percentage of Th17 and Tc17 cells in the lung was investigated.

\section{Materials and methods}

Mice. A total of 18 female BALB/c mice (weight, 18-21 g; age, 5-6 weeks) were obtained from the Laboratory Animal Center of the Hubei Province (Wuhan, China). All mice were housed in a specific pathogen-free facility in microisolator cages, an provided with autoclaved food and acidified water under a $12 \mathrm{~h}$ light/dark cycle. All experimental animal care and treatment protocols followed the guidelines established by the Institutional Animal Care and Use Committee of the Tongji Hospital (Wuhan, China). The ethics committee of Tongii Hospital.

Generation of asthmatic model and treatment. To generate an asthmatic model, mice were sensitized and challenged with OVA (Sigma-Aldrich, St. Louis, MO, USA) as previously reported (19). Briefly, the mice were sensitized by intraperitoneal injection with $100 \mu \mathrm{g}$ OVA and $1 \mathrm{mg}$ aluminium (Thermo Fisher Scientific, Inc., Waltham, MA, USA) in $200 \mu \mathrm{l}$ saline on days 0, 7 and 14. In the OVA group, the sensitized mice were then challenged by intranasal administration of $1 \mathrm{mg}$ OVA in $50 \mu \mathrm{l}$ saline on days 21, 22 and 23. In the control group, mice were challenged with $200 \mu \mathrm{l}$ saline alone. In the OVA + AMD3100 group, AMD3100 (Cayman chemical company, Ann Arbor, MI, USA) was freshly dissolved in saline and administered intraperitoneally at a dose of $10 \mathrm{mg} / \mathrm{kg}$ in $200 \mu \mathrm{l}$ saline $1 \mathrm{~h}$ prior to every challenge on days 21,22 and 23.

Determination of AHR. AHR to inhaled methacholine (Sigma-Aldrich) was measured using FlexiVent (SCIREQ Scientific Respiratory Equipment, Inc., Montréal, QC, Canada) (20). The mice were anesthetized by intraperitoneal injection of pentobarbital $(50 \mathrm{mg} / \mathrm{kg}$ ) (Wuhan Sanjiang Space Guge Biotech Co., Ltd., Wuhan, China), tracheotomized, and connected to the FlexiVent. Baseline airway resistance was measured in each mouse following nebulization (SCIREQ Scientific Respiratory Equipment, Inc.) of phosphate-buffered saline (PBS; vehicle for methacholine) for $10 \mathrm{sec}$ using an Aeroneb ultrasonic nebulizer (SCIREQ Scientific Respiratory Equipment, Inc.). Following baseline measurements, the mice were first exposed to nebulized saline, followed by increasing doses $(3,6,12$ and $25 \mathrm{mg} / \mathrm{ml})$ of nebulized methacholine for $3 \mathrm{~min}$ each. Breathing indices were read for $3 \mathrm{~min}$ following each nebulization, and the enhanced pause values were determined.

Collection of BALF and histological analysis. The mice were sacrificed $24 \mathrm{~h}$ by cervical dislocation following the last OVA or saline challenge. The lungs were lavaged 3 times with $0.8 \mathrm{ml}$ saline, and the collected cells were centrifuged at $300 \mathrm{x}$ g for $10 \mathrm{~min}$ at $4^{\circ} \mathrm{C}$. The total number of cells in BALF was counted by a hemacytometer. Eosinophils, lymphocytes, neutrophils and macrophages were counted in BALF using cytospins subjected to Wright-Giemsa staining (Wuhan Sanjiang Space Guge Biotech Co., Ltd.) at room temperature. Lung tissue samples were embedded in paraffin, cut into $5 \mathrm{~mm}$ sections using a microtome (Leica RM2016; Leica Biosystems, Wetzlar, Germany) and stained with hematoxylin and eosin (both purchased from Wuhan Sanjiang Space Guge Biotech Co., Ltd.). Airway inflammation was assessed using a light microscopy (BX53; Olympus Corporation, Tokyo, Japan).

Preparation of lung homogenate. The lung tissue suspensions were obtained as previously described (21). Briefly, the right lung was dissected prior to being rapidly frozen in liquid nitrogen and stored at $-80^{\circ} \mathrm{C}$. Following thawing, the lung tissue sample was homogenized in PBS and centrifuged at $800 \mathrm{x} \mathrm{g}$ for $15 \mathrm{~min}$ at $4^{\circ} \mathrm{C}$ to remove the sediments, and the supernatant was subsequently used for measurement of IL-17 concentration.

Measurement of cytokines. The levels of IL-4, IL-5 and IL-13 in the BALF, as well as those of IL-17 in the lung homogenates were determined by IL-4 (cat. no. 88-7044), IL-5 (cat. no. 88-7054), IL-13 (cat. no. 88-7137) and IL-17 (cat. no. 88-7371) ELISA kits (eBioscience, Inc., San Diego, CA, USA), according to the manufacturer's protocol. Briefly, samples were added to 96 -well microtiter plates precoated with monoclonal antibody to mouse IL-4, IL-5 and IL-13 or IL-17 and incubated for $2 \mathrm{~h}$ at room temperature. Subsequently, 96-well plates were washed, and Biotin-Conjugate and Streptavidin-HRP were added. After washing 6 times with PBS and 0.25\% Tween-20 (Wuhan Sanjiang Space Guge Biotech Co., Ltd.), $100 \mu 1$ TMB Substrate Solution was added to each well. The plate was incubated for $\sim 10 \mathrm{~min}$ in the dark and then $100 \mu \mathrm{l}$ of Stop Solution was added into each well. Finally, absorbance was determined at $450 \mathrm{~nm}$ using a microplate ELISA reader (ELx800; Bio-Rad Laboratories, CA, USA). IL-4, IL-5 and IL-13 or IL-17 concentrations were calculated from a standard curve.

Flow cytometric analysis. The mononuclear cells in the lung tissue samples were obtained as reported previously (22). The cells collected from the lung tissue samples were stimulated with phorbol myristate acetate (50 ng/ml; Sigma-Aldrich) and 


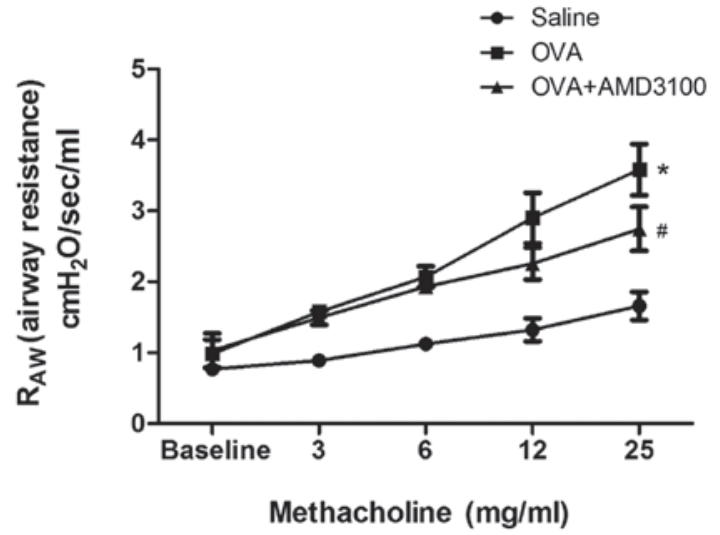

Figure 1. AMD3100 treatment reduces OVA-induced airway hyperresponsiveness. Saline, normal control mice treated with saline only; OVA, OVA-sensitized/challenged mice; OVA + ADM3100, ADM3100-treated and OVA-sensitized/challenged mice. ${ }^{*} \mathrm{P}<0.05$, vs. the saline group and ${ }^{\text {" }} \mathrm{P}<0.05$, vs. the OVA group. All data are presented as means \pm standard error of the mean for $\mathrm{n}=4-5$ mice/group. OVA, ovalbumin.

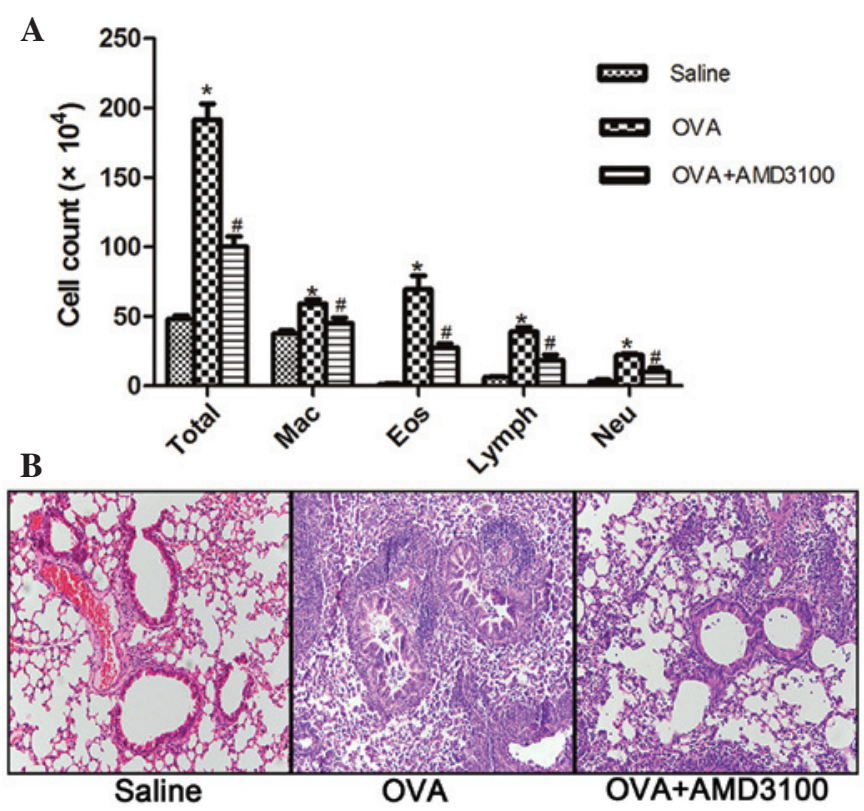

Figure 2. ADM3100 administration attenuates airway inflammation following OVA challenge. BALF and lung tissue samples were collected $24 \mathrm{~h}$ following the last challenge with OVA. (A) Differential cell counts for macrophages, eosinophils, lymphocytes and neutrophils were calculated from cytospin preparations. (B) Lung histopathology was assessed with hematoxylin and eosin (original magnification, $\mathrm{x} 200$ ). ${ }^{*} \mathrm{P}<0.05$, vs. the saline group and ${ }^{\#} \mathrm{P}<0.05$, vs. the OVA group. All data are presented as means \pm standard error of the mean for n=5-6 mice/group. OVA, ovalbumin; Mac, macrophages; Eos, eosinophils; Lymph, lymphocytes; Neu, neutrophils.

ionomycin $\left(1,000 \mathrm{ng} / \mathrm{ml}\right.$; Sigma-Aldrich) for $5 \mathrm{~h}$ at $37^{\circ} \mathrm{C}$ in an atmosphere containing $5 \% \mathrm{CO}_{2}$, and bovine serum albumin (50 ng/ml; Sigma-Aldrich) was then added to block the flow of cytokines from the cytoplasm. Following stimulation, the cells were stained with phycoerythrin (PE)-cyanine 5-conjugated anti-mouse CD3 antibody (1:20; cat. no. 17A2; Biolegend, Inc., San Diego, CA, USA) and fluorescein isothiocyanate-conjugated anti-mouse CD8 antibody (1:50; cat.no. 53-6.7; Biolegend, Inc.) for $30 \mathrm{~min}$ at $4^{\circ} \mathrm{C}$ in the dark. Following cell-surface staining, the cells were washed twice with washing buffer

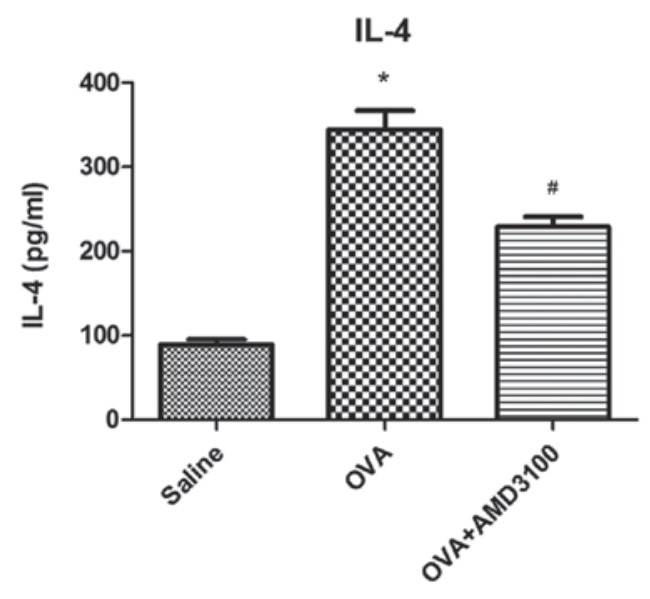

IL-5

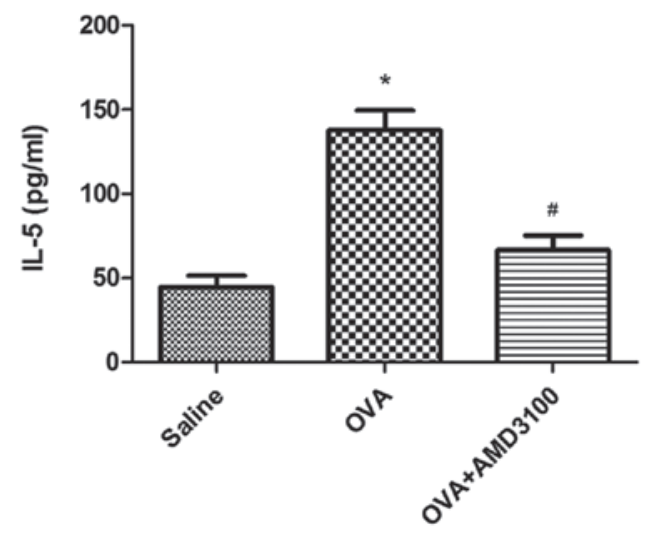

IL-13

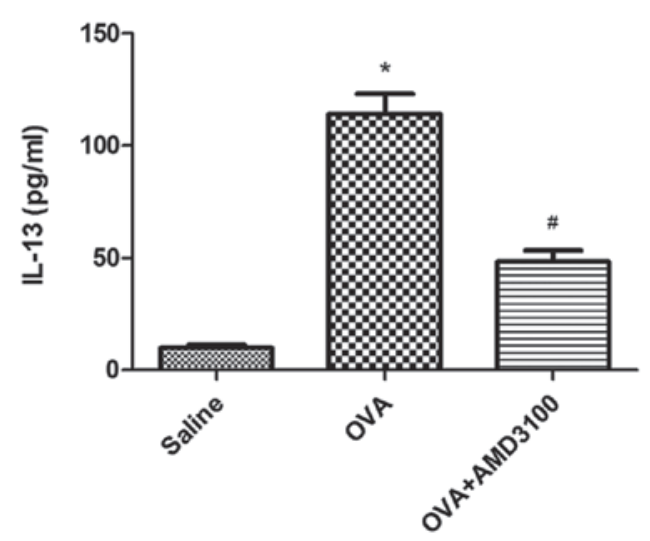

Figure 3. AMD3100 treatment decreases IL-4, IL-5 and IL-13 concentrations in the BALF. IL-4, IL-5 and IL-13 concentrations in the BALF were assessed $24 \mathrm{~h}$ following the last challenge with OVA. IL-4, IL-5 and IL-13 production significantly increased in the BALF following OVA sensitization and challenge, and this increase was significantly reduced by treatment with AMD3100. ${ }^{*} \mathrm{P}<0.01$, vs. the saline group and ${ }^{\#} \mathrm{P}<0.05$, vs. the OVA group. Results are presented as the means \pm standard error of the mean for $n=5-6$ mice/group. IL, interleukin; OVA, ovalbumin; BALF, bronchoalveolar lavage fluid.

(Biolegend, Inc.), fixed and permeabilised with Fix-Perm solution (BD Biosciences, San Jose, CA, USA) for intracellular staining with PE-conjugated anti-mouse IL-17 antibody (1:100; cat. no. TC11-18H10.1; eBioscience) for $30 \mathrm{~min}$ at $4^{\circ} \mathrm{C}$ in the dark. The stained cells were used for flow cytometric analysis (BD LSR II; BD Biosciences) in order to determine the number of Th17 and Tc17 lymphocytes. CD8 ${ }^{+} \mathrm{T}$ lymphocytes were 

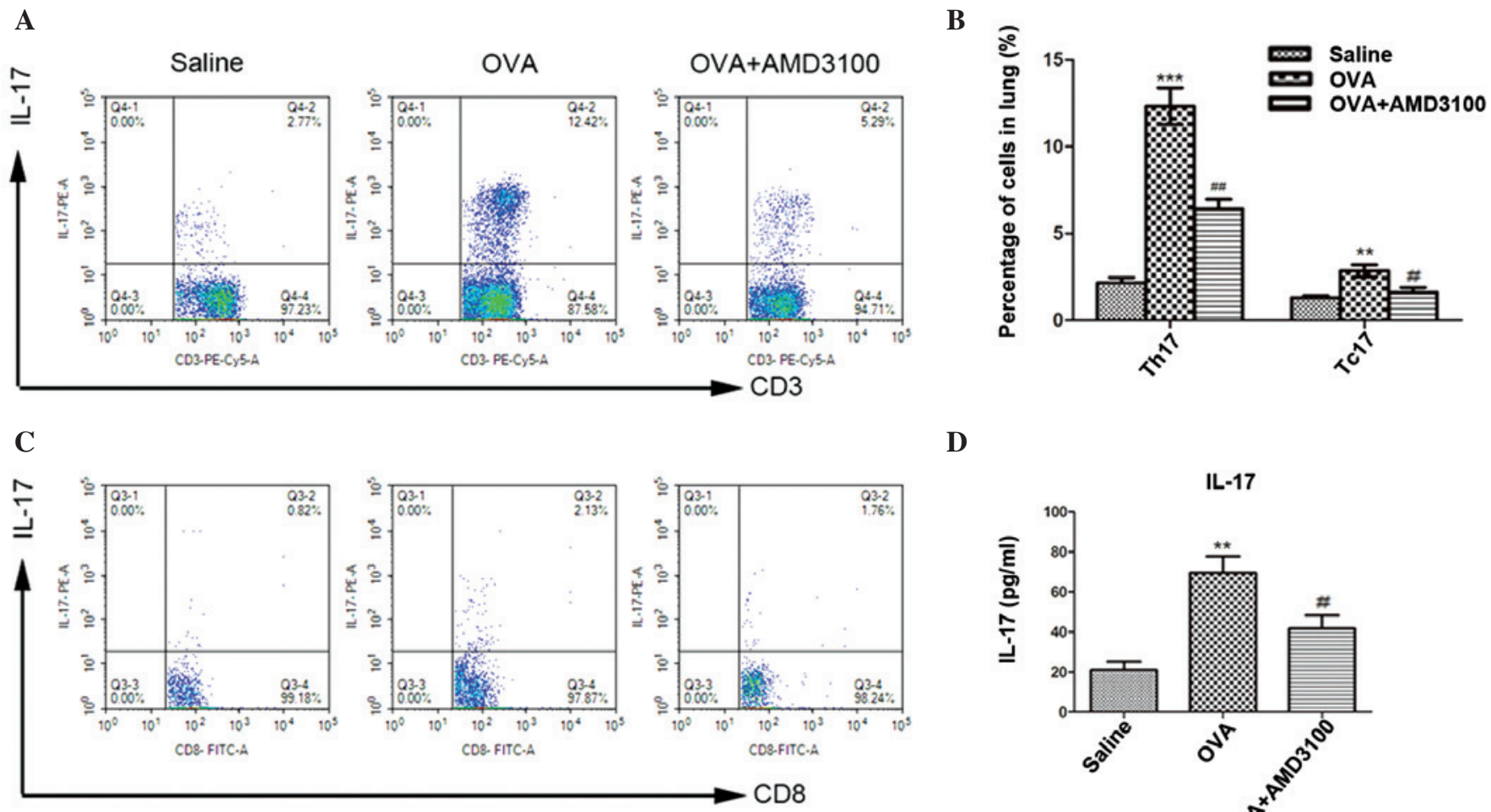

D

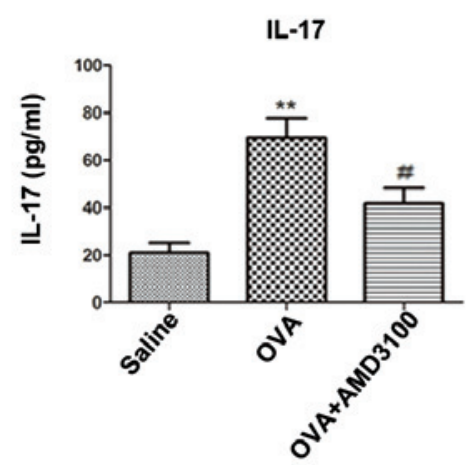

Figure 4. AMD3100 treatment attenuates the development of Th17 and Tc17 cells and decreases the concentration of IL-17 in the lung. (A and C) Representative plots and (B) combined data of Th17 and Tc17 numbers in the lung. IL-17 concentration in the lung homogenate assessed $24 \mathrm{~h}$ following the last challenge with OVA. (D) Marked increases in IL-17 production in the lung homogenate following OVA sensitization and challenge were significantly suppressed by treatment with AMD3100 as compared with the saline groups. ${ }^{* * * *} \mathrm{P}<0.001$, vs. the saline group; ${ }^{* * *} \mathrm{P}<0.01$, vs. the saline group; ${ }^{\# \#} \mathrm{P}<0.05$, vs. the OVA group; ${ }^{"} \mathrm{P}<0.05$, vs. the OVA group. All data are presented as means \pm standard error of the mean of $\mathrm{n}=4-5$ mice/group. Th17, T-helper 17 cell; Tc17, T-cytotoxic 17 cell; IL, interleukin; OVA, ovalbumin.

specifically gated, the $\mathrm{CD} 3^{+} \mathrm{CD} 8 \mathrm{IL}^{-} 7^{+} \mathrm{T}$ lymphocytes were counted as Th17 cells, and the $\mathrm{CD}^{+} \mathrm{CD} 8^{+} \mathrm{IL}-17^{+} \mathrm{T}$ lymphocytes were counted as Tc17 cells.

Statistical analysis. All data were presented as means \pm standard error of the mean. Data analysis was performed using GraphPad Prism version 5.0 (GraphPad Software, Inc., La Jolla, CA, USA). Statistical differences were assessed by one-way analysis of variance. $\mathrm{P}<0.05$ was considered to indicate a statistically significant result.

\section{Results}

Treatment with AMD3100 reduced AHR in experimental asthma. To determine the effects of AMD3100 on AHR, airway resistance was measured $24 \mathrm{~h}$ following the last challenge with OVA. In OVA-challenged mice, airway resistance was increased in a dose-dependent manner following exposure to methacholine. However, AMD3100 treatment inhibited the increased airway reactivity to methacholine induced by OVA (Fig. 1).

Administration of AMD3100 decreases airway inflammation. ADM3100 administration significantly reduced total cell counts and eosinophil counts in the BALF following OVA sensitization and challenge (Fig. 2A). These changes can also be observed by histological examination of the lung tissue samples from the treated animals; after treatment with
ADM3100, inflammatory cell infiltration was inhibited around the airway (Fig. 2B).

Administration of AMD3100 reduces the production of Th2 cytokines. As shown in Fig. 3, the levels of IL-4, IL-5 and IL-13 were significantly increased in OVA-challenged mice, compared with the controls. Administration of AMD3100 significantly reduce these increased levels of IL-4, IL-5 and IL-13 in the BALF of OVA-challenged mice.

AMD3100 suppresses the development of Th17 and Tc17 cells in the lung and IL-17 production in lung homogenates. To investigate the effect of administration of AMD3100 on the development of Th17 and Tc17 cells, $\mathrm{CD}^{+}{ }^{+} \mathrm{CD} 8^{-}$and $\mathrm{CD}^{+} \mathrm{CD}^{+} \mathrm{T}$ cells were isolated from the lung and gated for expression of IL-17 to compare saline, OVA, and OVA + AMD3100 treatment groups. OVA sensitization and challenge markedly increased Th17 and Tc17 cells in the lung compared with the saline-sensitized and challenged mice. However, this marked increase in Th17 and Tc17 cells was attenuated by AMD3100 administration, which resulted in a significant decrease in the percentage of Th17 and Tc17 cells compared with OVA-challenged mice (Fig. 4A-C). Furthermore, as shown in Fig. 4D, the levels of IL-17 in the lung homogenate were significantly increased in OVA-challenged mice compared with negative controls. Administration of AMD3100 significantly decreased the levels of IL-17 in the lung homogenate of OVA-challenged mice $(\mathrm{P}<0.01)$. 


\section{Discussion}

Previous reports have demonstrated that inhibition of CXCL12/CXCR4 signaling attenuated allergic lung inflammation and AHR $(5,6,23)$. However, the exact underlying mechanisms have yet to be fully understood. The present study investigated whether inhibition of CXCL12/CXCR4 signaling was able to attenuate OVA-induced airway inflammation and AHR by decreasing Th17 and Tc17 pro-inflammatory response. Using a murine model of asthma, the results demonstrated that administration of AMD3100 attenuated allergic airway inflammation along and significantly suppressed Th17 and Tc17 cell infiltration into the lung tissues, as well as decreased IL-17 levels in the lung. These results provide an improved understanding of the mechanisms underlying CXCL12/CXCR4 signaling in the pathogenesis of asthma.

AMD3100 is a soluble CXCR4 inhibitor, which inhibits binding of CXCL12 to CXCR4 and subsequent signal transduction (24). AMD3100 was shown to attenuate allergic pulmonary inflammation and AHR (5). In the present study, the results demonstrated that treatment with AMD3100 prior to allergen challenge significantly decreased airway inflammatory cell accumulation and AHR. The results of the present study were concordant with those of a previous study that demonstrated that specific inhibition of CXCR4 with AMD3100 reduced the number of pathological parameters associated with asthmatic-type inflammation (5). Based on both the results of the present and previous study (5), AMD3100 may effectively inhibit experimental allergic asthma in mice, however, the possible mechanisms underlying this process have yet to be fully understood.

Th17 cell is a type of $\mathrm{CD}^{+} \mathrm{T}$ cell subset, and has been defined by its secreted product, IL-17 (25). In addition to Th17 cells, there are $\mathrm{CD} 8^{+} \mathrm{T}$ cells named Tc17 cells (26), which also produce IL-17. Th17 cells and Tc17 cells share many similar characteristics, including production of IL-17 (27). Accumulating data suggests that Th17 or Tc17 cells may have an important role in the development of various allergic diseases that have classically been considered to be Th1- or Th2-mediated disorders (28-30). Our recent study also demonstrated an increased proportion of Th17 and Tc17 cells in the peripheral blood of patients with asthma compared with healthy controls, as well as in the spleen cells and lung tissues of asthmatic mice, which suggested that a functional disequilibrium between Th17 and Tc17 cell subsets may contribute to the allergic inflammatory process in asthma (18). Both Th17 and Tc17 cells likely contribute to the immune response in asthma since both have the ability to produce IL-17.

To determined whether the suppression of allergic airway responses induced by AMD3100 is associated with the presence of Th17 and Tc17 cells, the present study investigated the expression levels of Th17 and Tc17 cells in a murine allergic asthma model. The results demonstrated that treatment with AMD3100 attenuated allergic airway inflammation and significantly suppressed Th17 and Tc17 cell recruitment in mice. To the best of our knowledge, this is the first study to report an association between CXCL12 signaling and Th17/Tc17 cells. This investigation provides novel insight into the mechanisms underlying the involvement of the
CXCL12/CXCR4 signaling pathway in asthmatic responses during the course of disease development.

In conclusion, the data of the present investigation suggested that inhibition of CXCL12/CXCR4 signaling could suppress the in vivo development of Th17 and Tc17 cells. These findings also provide further support for an anti-inflammatory role of AMD3100 as a CXCR4 inhibitor in the treatment of asthma. However, further studies are required in order to explore the precise mechanisms underlying these processes.

\section{Acknowledgements}

The present study was supported by the National Natural Science Foundation of China (grant nos. 81170021 and 30900647).

\section{References}

1. Wills-Karp M, Nathan A,Page K and Karp CL: New insights into innate immune mechanisms underlying allergenicity. Mucosal Immunol 3: 104-110, 2010.

2. Shirozu M, Nakano T, Inazawa J, Tashiro K, Tada H, Shinohara T and Honjo T: Structure and chromosomal localization of the human stromal cell-derived factor 1 (SDF1) gene. Genomics 28: 495-500, 1995.

3. McQuibban GA, Butler GS, Gong JH, Bendall L, Power C, Clark-Lewis I and Overall CM: Matrix metalloproteinase activity inactivates the CXC chemokine stromal cell-derived factor-1. J Biol Chem 276: 43503-43508, 2001.

4. Daubeuf F, Hachet-Haas M, Gizzi P, Gasparik V, Bonnet D, Utard V, Hibert M, Frossard N and Galzi JL: An antedrug of the CXCL12 neutraligand blocks experimental allergic asthma without systemic effect in mice. J Biol Chem 288: 11865-11876, 2013.

5. Lukacs NW, Berlin A, Schols D, Skerlj RT and Bridger GJ: AMD3100, a CxCR4 antagonist, attenuates allergic lung inflammation and airway hyperreactivity. Am J Pathol 160: 1353-1360, 2002.

6. Gonzalo JA, Lloyd CM, Peled A, Delaney T, Coyle AJ and Gutierrez-Ramos JC: Critical involvement of the chemotactic axis CXCR4/stromal cell-derived factor-1 alpha in the inflammatory component of allergic airway disease. J Immunol 165: 499-508, 2000.

7. Negrete-Garcia MC, Velazquez JR, Popoca-Coyotl A, Montes-Vizuet AR, Juárez-Carvajal E and Teran LM: Chemokine (C-X-C motif) ligand 12/stromal cell-derived factor-1 is associated with leukocyte recruitment in asthma. Chest 138: 100-106, 2010.

8. Molet S, Hamid Q, Davoine F, Nutku E, Taha R, Pagé N, Olivenstein R, Elias $\mathbf{J}$ and Chakir J: IL-17 is increased in asthmatic airways and induces human bronchial fibroblasts to produce cytokines. J Allergy Clin Immunol 108: 430-438, 2001.

9. Chakir J, Shannon J, Molet S, Fukakusa M, Elias J, Laviolette M, Boulet LP and Hamid Q: Airway remodeling-associated mediators in moderate to severe asthma: Effect of steroids on TGF-beta, IL-11, IL-17 and type I and type III collagen expression. J Allergy Clin Immunol 111: 1293-1298, 2003.

10. Nakae S, Komiyama Y, Nambu A, Sudo K, Iwase M, Homma I, Sekikawa K, Asano M and Iwakura Y: Antigen-specific T cell sensitization is impaired in IL-17-deficient mice, causing suppression of allergic cellular and humoral responses. Immunity 17: 375-387, 2002.

11. Barczyk A, Pierzchala W and Sozanska E: Interleukin-17 in sputum correlates with airway hyperresponsiveness to methacholine. Respir Med 97: 726-733, 2003.

12. Schnyder-Candrian S, Togbe D, Couillin I, Mercier I, Brombacher F, Quesniaux V, Fossiez F, Ryffel B and Schnyder B: Interleukin-17 is a negative regulator of established allergic asthma. J Exp Med 203: 2715-2725, 2006.

13. Wakashin H, Hirose K, Maezawa Y, Kagami S, Suto A, Watanabe N, Saito Y, Hatano M, Tokuhisa T, Iwakura Y, et al: IL-23 and Th17 cells enhance Th2-cell-mediated eosinophilic airway inflammation in mice. Am J Respir Crit Care Med 178: 1023-1032, 2008. 
14. Weaver CT, Harrington LE, Mangan PR, Gavrieli M and Murphy KM: Th17: An effector CD4 T cell lineage with regulatory T cell ties. Immunity 24: 677-688, 2006.

15. Langrish CL, Chen Y, Blumenschein WM, Mattson J, Basham B, Sedgwick JD, McClanahan T, Kastelein RA and Cua DJ: IL-23 drives a pathogenic $\mathrm{T}$ cell population that induces autoimmune inflammation. J Exp Med 201: 233-240, 2005.

16. Aggarwal S, Ghilardi N, Xie MH, de Sauvage FJ and Gurney AL: Interleukin-23 promotes a distinct CD4 T cell activation state characterized by the production of interleukin-17. J Biol Chem 278 1910-1914, 2003.

17. Huber M, Heink S, Grothe H, Guralnik A, Reinhard K, Elflein K, Hünig T, Mittrücker HW, Brüstle A, Kamradt T and Lohoff M: A Th17-like developmental process leads to CD8(+) Tc17 cells with reduced cytotoxic activity. Eur J Immunol 39: 1716-1725, 2009.

18. Li K, Wang Z, Cao Y, Bunjhoo H, Zhu J, Chen Y, Xiong S, Xu Y and Xiong W: The study of the ratio and distribution of Th17 cells and Tc17 cells in asthmatic patients and the mouse model. Asian Pac J Allergy Immunol 31: 125-131, 2013.

19. Gong S, Li J, Ma L, Li K, Zhang L, Wang G, Liu Y, Ji X, Liu X, Chen $\mathrm{P}$, et al: Blockade of dopamine D1-like receptor signalling protects mice against OVA-induced acute asthma by inhibiting B-cell activating transcription factor signalling and Th17 function. FEBS J 280: 6262-6273, 2013

20. Kramer EL, Mushaben EM, Pastura PA, Acciani TH, Deutsch GH Khurana Hershey GK, Korfhagen TR, Hardie WD, Whitsett JA and Le Cras TD: Early growth response-1 suppresses epidermal growth factor receptor-mediated airway hyperresponsiveness and lung remodeling in mice. Am J Respir Cell Mol Biol 41: 415-425, 2009.

21. You QH, Zhang D, Niu CC, Zhu ZM, Wang N, Yue Y and Sun GY: Expression of IL-17A and IL-17F in lipopolysaccharide-induced acute lung injury and the counteraction of anisodamine or methylprednisolone. Cytokine 66: 78-86, 2014.
22. Sauer KA, Scholtes P, Karwot R and Finotto S: Isolation of CD4+ T cells from murine lungs: A method to analyze ongoing immune responses in the lung. Nat Protoc 1: 2870-2875, 2006.

23. Daubeuf F, Hachet-Haas M, Gizzi P, Gasparik V, Bonnet D, Utard V, Hibert M, Frossard N and Galzi JL: An antedrug of the CXCL12 neutraligand blocks experimental allergic asthma without systemic effect in mice. J Biol Chem 288: 11865-11876, 2013

24. Heesen M, Berman MA, Höpken UE, Gerard NP and Dorf ME: Alternate splicing of mouse fusin/CXC chemokine receptor-4: Stromal cell-derived factor-1alpha is a ligand for both CXC chemokine receptor-4 isoforms. J Immunol 158: 3561-3564, 1997.

25. Weaver CT: Th17: The ascent of a new effector T-cell subset. Preface. Eur J Immunol 39: 634-636, 2009.

26. Yen HR, Harris TJ, Wada S, Grosso JF, Getnet D, Goldberg MV, Liang KL, Bruno TC, Pyle KJ, Chan SL, et al: Tc17 CD8 T cells: Functional plasticity and subset diversity. J Immunol 183: 7161-7168, 2009.

27. Yamashita N and Clement LT: Phenotypic characterization of the post-thymic differentiation of human alloantigen-specific CD8+ cytotoxic T lymphocytes. J Immunol 143: 1518-1523, 1989.

28. Zhao Y, Yang J and Gao YD: Altered expressions of helper $\mathrm{T}$ cell $(\mathrm{Th}) 1$, Th2, and Th17 cytokines in CD8 $(+)$ and $\gamma \delta \mathrm{T}$ cells in patients with allergic asthma. J Asthma 48: 429-436, 2011.

29. Oboki K, Ohno T, Saito H and Nakae S: Th17 and allergy. Allergol Int 57: 121-134, 2008.

30. Zhao Y, Balato A, Fishelevich R, Chapoval A, Mann DL and Gaspari AA: Th17/Tc17 infiltration and associated cytokine gene expression in elicitation phase of allergic contact dermatitis. Br J Dermatol 161: 1301-1306, 2009. 